Acta Crystallographica Section F

Structural Biology

and Crystallization

Communications

ISSN 1744-3091

\section{Towards the structure of the C-terminal part of the S-layer protein SbsC}

\section{Markus Kroutil, ${ }^{\mathrm{a}}$ Tea Pavkov, ${ }^{\mathrm{a}}$ T \\ Ruth Birner-Gruenberger, ${ }^{b}$ Manfred Tesarz, ${ }^{\text {c Uwe B. Sleytr, }}$ Eva M. Egelseer ${ }^{c}$ and Walter Keller $^{\text {a* }}$}

${ }^{\mathbf{a}}$ Karl-Franzens University, Institute of Molecular Biosciences, Graz, Austria, ${ }^{\mathbf{b}}$ Medical University of Graz, Center for Medical Research, Proteomics Core Facility, Graz, Austria, and ${ }^{\mathbf{c}}$ Department of NanoBiotechnology, University of Natural Resources and Applied Life Sciences, Vienna, Austria

₹ These authors contributed equally to this work.

Correspondence e-mail: walter.keller@uni-graz.at

Received 2 May 2009 Accepted 2 September 2009

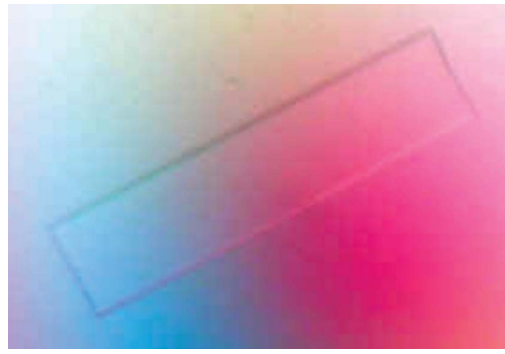

(C) 2009 International Union of Crystallography All rights reserved
The S-layer protein SbsC from Geobacillus stearothermophilus ATCC 12980 is the most prevalent single protein produced by the bacterium and covers the complete bacterial surface in the form of a two-dimensional crystalline monolayer. In order to elucidate the structural features of the assembly domains, several N-terminally truncated fragments of $\mathrm{SbsC}$ have been crystallized. Crystals obtained from recombinant fragments showed anisotropic diffraction to a maximum of $3.5 \AA$ resolution using synchrotron radiation. The best diffracting crystals were obtained from $\mathrm{rSbsC}_{(755-1099)}$, an unintentional in situ proteolytic degradation product of $\mathrm{rSbsC}_{(447-1099)}$. Crystals were obtained in two different space groups, $P 2_{1}$ and $P 4_{1} 2_{1} 2$, and diffracted to 2.6 and $3 \AA$ resolution, respectively. Native and heavy-atom derivative data have been collected. The structure of the C-terminal part will yield atomic resolution information for the domains that are crucial for the assembly of the two-dimensional lattice.

\section{Introduction}

Crystalline bacterial cell-surface layers, termed S-layers (Sleytr, 1978), have been observed in species of nearly every taxonomical group of walled bacteria and represent an almost universal feature of archaeal envelopes (Sleytr \& Beveridge, 1999; Sleytr et al., 1993; Sára \& Sleytr, 2000; Messner et al., 2009; Avall-Jaaskelainen \& Palva, 2005; Claus et al., 2005). These monomolecular isoporous structures are composed of a single protein or glycoprotein species with a molecular mass in the range 40-200 kDa. Electron-microscopy studies revealed that S-layer lattices can have oblique $(p 1, p 2)$, square $(p 4)$ or hexagonal $(p 3, p 6)$ symmetry, with a centre-to-centre spacing of the morphological units of approximately 3-35 nm. Depending on the lattice type, the morphological units constituting S-layers consist of one, two, three, four or six identical protein or glycoprotein subunits. Even after isolation from the cell wall, S-layer proteins frequently maintain the ability to self-assemble in suspension in vitro or to recrystallize on peptidoglycan-containing sacculi (Sleytr, 1975; Sleytr \& Glauert, 1975), at the air-water interface or on artificial solid supports (Sleytr et al., 2005, 2007). These general principles of S-layers have led to a broad spectrum of applications in life sciences and non-life sciences (Sleytr et al., 1999, 2002, 2007; Sleytr, Pum et al., 2001; Sleytr, Sára et al., 2001; Schuster \& Sleytr, 2006; Sára, Egelseer et al., 2006; Sára, Pum et al., 2006; Egelseer et al., 2009; Bohle et al., 2004).

Although the role of S-layers in nature is not completely clear, it is now recognized that $S$-layer lattices can provide the organism with a selective advantage by functioning as (i) protective coats, (ii) structures involved in cell adhesion and surface recognition, (iii) molecular sieves, (iv) molecule and ion traps, (v) scaffolding for enzymes and (vi) virulence factors in pathogenic organisms (Sleytr et al., 1993, 1996, 2002; Sleytr \& Sára, 1997; Messner \& Sleytr, 1992; Beveridge \& Koval, 1993; Beveridge, 1994). For archaea that possess S-layers as the exclusive wall component, S-layer (glyco)protein lattices determine cell shape and the cell-fission process (Messner et al., 1986) and probably act as exoskeletons (Engelhardt, 2007; Pum et al., 1991).

In spite of their ubiquitous appearance in nature and their obvious importance in many prokaryotic organisms, high-resolution structural information for this class of proteins is very rare. Apart from the 
recently determined structure of bacterial S-layer fragments from Geobacillus stearothermophilus ATCC 12980 (Pavkov et al., 2008) and Clostridium difficile (Fagan et al., 2009), only two recombinant archaeal S-layer fragments from Staphylothermus marinus (Stetefeld et al., 2000) and Methanosarcina mazei (Jing et al., 2002) have been structurally determined.

One of the best-studied systems, the Gram-positive bacterial species G. stearothermophilus, is frequently endowed with an S-layer as the outermost cell-envelope component. The cell surface of G. stearothermophilus ATCC 12980 is completely covered with an oblique lattice formed by the S-layer protein SbsC (Egelseer et al., 1996). The protein precursor includes a 30-amino-acid signal peptide and consists of 1099 amino acids (Jarosch et al., 2000). The mature protein exhibits a molecular mass of $112.5 \mathrm{kDa}$ and an isoelectric point of 5.5. As evaluated by surface plasmon resonance spectroscopy and isothermal titration calorimetry, the positively charged $\mathrm{N}$-terminal region of $\mathrm{SbsC}$ binds specifically to a negatively charged secondary cell-wall polymer (SCWP; Ferner-Ortner et al., 2007; Pavkov et al., 2008) consisting of $N$-acetyl glucosamine (GlcNAc), glucose and 2,3-dideoxy-diacetamido mannosamine uronic acid (Schäffer et al., 1999) that is covalently linked to the peptidoglycan backbone. Furthermore, this S-layer protein exhibits adhesion sites for a high-molecular-mass exoamylase (HMMA; Egelseer et al., 1996; Ferner-Ortner-Bleckmann et al., 2009).

After the S-layer gene $s b s C$ had been sequenced, the corresponding S-layer protein SbsC was the first for which different $\mathrm{N}$ - or C-terminally truncated S-layer protein forms were recombinantly produced and systematically surveyed for their self-assembly and recrystallization properties (Jarosch et al., 2001). Initial truncated constructs of SbsC were generated randomly since no homologous structure was available and a reliable prediction of the domain borders could not be obtained (Jarosch et al., 2001). Two recombinant soluble fragments, $\mathrm{rSbsC}_{(31-844)}$ and $\mathrm{rSbsC}_{(447-1099)}$, could be crystallized (Pavkov et al., 2003; Fig. 1). The structure of the C-terminally truncated fragments $\mathrm{rSbsC}_{(31-844)}$ was determined, revealing six domains arranged like beads on a string and connected by short flexible linkers (Pavkov et al., 2008). The quality of the electrondensity map for the last three domains was poor and only putative domain borders could be determined.

In order to obtain high-resolution structural information on the C-terminal part of the protein containing the assembly domains, diffraction-quality crystals of N-terminally truncated constructs were needed. Here, we report the different crystal forms obtained from soluble recombinant N-terminally truncated SbsC fragments (Fig. 1). Because of the initially unknown domain borders and the inherent flexibility of the S-layer protein, most diffraction data were com- promised by anisotropy. The only fragment that yielded diffractionquality crystals of sufficiently high resolution for structure determination was $\mathrm{rSbs}_{(755-1099)}$, which was obtained by unintentional in situ proteolytic degradation of $\operatorname{rSbsC}_{(447-1099) \text {. }}$

\section{Protein purification and characterization}

The cloning, expression and purification of $\operatorname{rSbsC}_{(447-1099)}$ have been described elsewhere (Jarosch et al., 2001; Pavkov et al., 2003). Based on the structure of $\mathrm{rSbsC}_{(31-844)}$, two new N-terminal truncation constructs, $\mathrm{rSbsC}_{(541-1099)}$ and $\mathrm{rSbsC}_{(638-1099)}$, were cloned and expressed according to published protocols (Jarosch et al., 2001). The genes encoding $\mathrm{rSbsC}_{(541-1099)}$ and $\mathrm{rSbsC}_{(638-1099)}$ were PCRamplified using the respective oligonucleotide forward primer $r$ SbsC541forw (5'-CGG AAT TCC ATG GTT ACT AAG ACA ATC CCT GTG AC-3') or $r$ SbsC638forw (5'-CGG AAT TCC ATG GTT AAA GTA CCT GTA AAT GTA GTT GC-3') in combination with the reverse primer $r$ SbsC1099rev (5'-GAC CGC TCG AGT TAC GAT GCT GAT TTT GTA CCA ATT TG-3') (for both genes) which introduced restriction sites (in bold) for $\mathrm{NcoI}$ (including an ATG start codon) and XhoI at the $5^{\prime}$ and $3^{\prime}$ ends, respectively. For cloning, the resulting PCR products were ligated with plasmid pET28a+ (Novagen). For expression, the recombinant plasmids were established in Escherichia coli One Shot BL21 Star (DE3) (Invitrogen).

Purification of the recombinant proteins was essentially performed as described in Pavkov et al. (2003), with slight modifications. For precipitation from the soluble fraction, the ammonium sulfate saturation was $30-60 \%$ for $\operatorname{rSbsC}_{(541-1099)}$ and $20-90 \%$ for $\mathrm{rSbsC}_{(638-1099)}$. Furthermore, the lyophilization step between the two purification steps via size-exclusion chromatography was eliminated.

Purified $\mathrm{rSbsC}_{(447-1099)}$ which was kept at $277 \mathrm{~K}$ and $5 \mathrm{mg} \mathrm{ml}^{-1}$ in Milli-Q water (Millipore, Billerica, Massachusetts, USA) for ten months showed severe degradation caused by an unidentified protease (or proteases). The degraded sample contained two major stable degradation products, as shown by SDS-PAGE (Fig. 2a). The degradation fragments were purified by size-exclusion chromatography on a Superdex 200 HR 10/30 column (GE Healthcare, Uppsala, Sweden) run under $10 \mathrm{~m} M$ HEPES-NaOH $\mathrm{pH} 7$ and $150 \mathrm{mM} \mathrm{NaCl}$ (Fig. 2b) and were characterized by N-terminal sequencing and mass spectrometry. N-terminal sequencing yielded the sequence VIDTTL for the longer fragment (lane 2, Fig. 2a) and VDVEVI for the shorter fragment (lane 3, Fig. 2a), corresponding to cutting sites at positions 755 and 751 in the SbsC sequence, respectively. Analysis of the two fragments by MALDI-TOF mass spectrometry [Ultraflextreme (Bruker Daltonics, Bremen, Germany) in

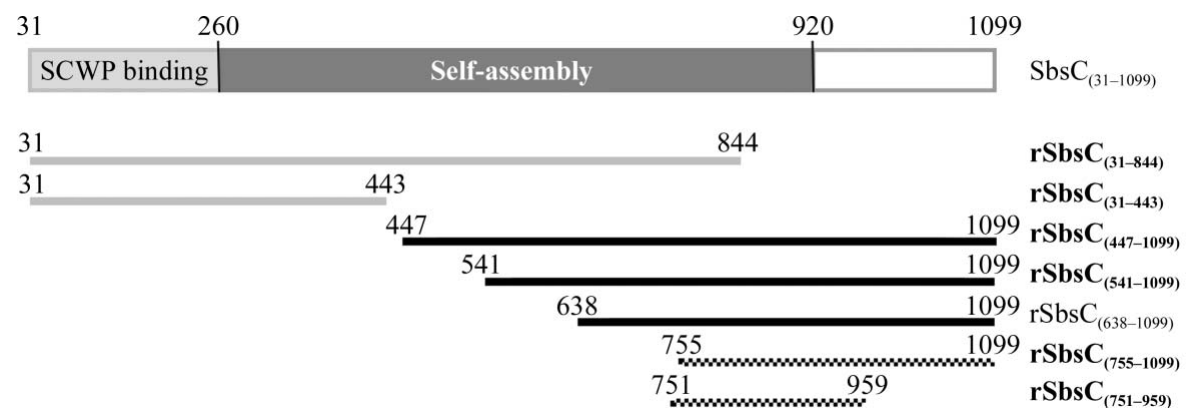

Figure 1

Graphical representation of the $\mathrm{SbSC}$ protein and recombinant truncation fragments. The native mature S-layer protein $\mathrm{SbsC}_{(31-1099)}$ is shown with the secondary cell-wall polymer (SCWP) binding and self-assembly regions indicated. C-terminal truncation fragments are shown in grey, N-terminal truncation fragments are shown in black and the fragments obtained by unintentional proteolysis are shown as hatched lines. Start and end positions are indicated above the individual fragments. Fragments for which crystals were obtained are indicated in bold. 
linear mode using sinapinic acid matrix] yielded a molecular weight (MW) of $35142 \mathrm{Da}$ for the longer fragment, indicating that it contains all amino acids from 755 to 1099 , the original C-terminal end of SbsC (theoretical MW $35138 \mathrm{Da}$; error $4 \mathrm{Da}$, corresponding to 114 p.p.m.). The MW of the shorter fragment was determined to be $21333 \mathrm{Da}$, corresponding to a peptide spanning residues 751-959 (theoretical MW $21335 \mathrm{Da}$; error $2 \mathrm{Da}$, corresponding to 94 p.p.m.). The purified fragments were dialyzed against Milli-Q water and concentrated to $7.1 \mathrm{mg} \mathrm{ml}^{-1}$ for $\operatorname{rSbsC}_{(755-1099)}$ and $6 \mathrm{mg} \mathrm{ml}^{-1}$ for $\mathrm{rSbsC}_{(751-959)}$ and subjected to crystallization trials.

\section{Crystallization}

Screening of all five fragments was performed in microbatch using an Oryx 6 robot (Douglas Instruments, Hungerford, England) and commercial Index Screens (Hampton Research, Aliso Viejo, California, USA). Conditions yielding crystals were refined in microbatch as well as in sitting-drop vapour-diffusion setups at $293 \mathrm{~K}$. The drop size was $1 \mu \mathrm{l}$ in all setups and the protein content was $50 \%$. Vapourdiffusion refinement was set up in CrystalClear Strips (Douglas Instruments) using $100 \mu \mathrm{l}$ reservoir solution. Microbatch refinement was set up in microbatch plates (Douglas Instruments) and a mixture of paraffin and silicon oil (both supplied by Hampton Research) in a 3:1 ratio was used.

Crystallization of $\mathrm{rSbsC}_{(447-1099)}\left(5 \mathrm{mg} \mathrm{ml}^{-1}\right)$ resulted in two conditions: (i) $100 \mathrm{~m} M$ sodium acetate $\mathrm{pH}$ 4.2, $50 \mathrm{mM}$ ammonium sulfate, $12-15 \%$ PEG 4000 and (ii) $100-200 \mathrm{~m} M$ zinc acetate, $100 \mathrm{~m} M$ Tris$\mathrm{HCl} \mathrm{pH} 8.5,15-18 \%$ PEG 4000. The crystals appeared in 1-6 d. $15 \%$ glycerol was used as a cryoprotectant for data collection for both conditions. The best diffracting crystals were obtained from the first condition, showing a rather anisotropic diffraction pattern with a resolution limit of $3.5 \AA$ in the best direction and of $7 \AA$ in the worst direction. In order to obtain higher resolution structural information, the shorter truncation constructs were submitted to crystallization trials. $\mathrm{rSbsC}_{(541-1099)}$ at $7.5 \mathrm{mg} \mathrm{ml}^{-1}$ in Milli-Q water was crystallized using Index Screen condition $1(0.1 M$ citric acid pH 3.5, $2 M$ ammonium sulfate). Crystals appeared after $7 \mathrm{~d}$ and diffracted to $5 \AA$ resolution under cryoconditions $(15 \%$ glycerol dissolved in Index Screen condition 1 ). No crystals were obtained using commercially available screens for the shorter fragment $\mathrm{rSbsC}_{(638-1099)}$.

The fragments obtained by purification of the proteolytic degradation products of $\mathrm{rSbsC}_{(447-1099)}$ were crystallized using Index Screen (Hampton Research). While the crystals from the shorter
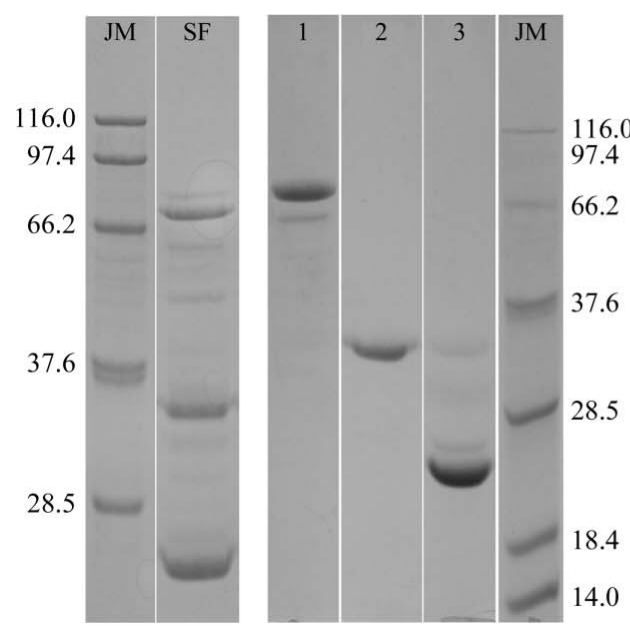

(a)

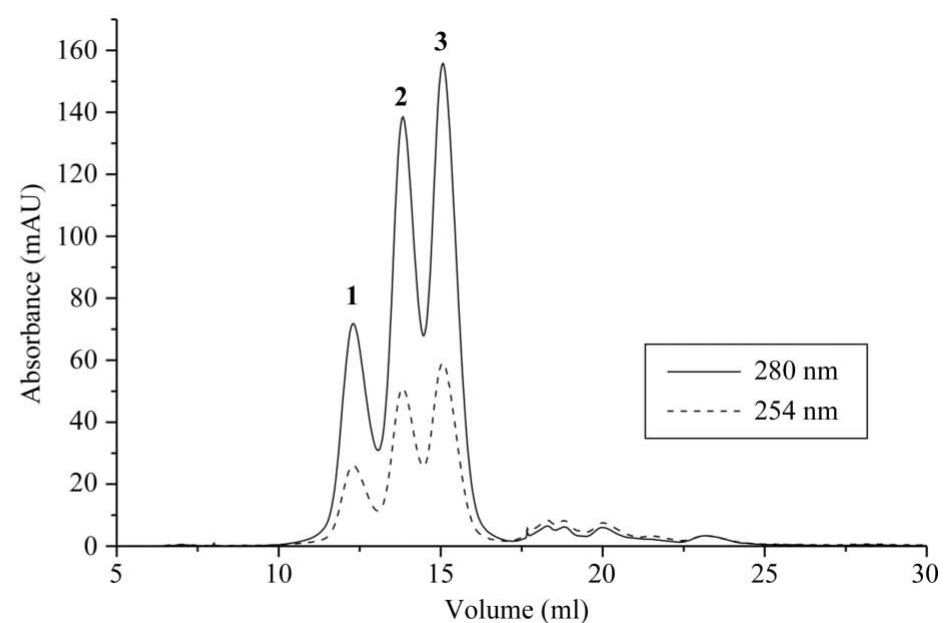

(b)

Figure 2

Unintentional in situ proteolytic cleavage and purification of the cleavage products. (a) $12 \%$ SDS-PAGE gels of degraded rSbsC $(447-1099)$ : lane JM, molecular-weight markers $(\mathrm{kDa})$ from Jena Bioscience (Jena, Germany); lane SF, start fraction before gel filtration; lane 1, $\mathrm{rSbsC}_{(447-1099)}$; lane 2, $\mathrm{rSbsC}_{(755-1099)}$; lane 3, $\mathrm{rSbsC}_{(751-959)}$. $\left(\right.$ b) $\mathrm{UV}_{\text {trace of }}$ the gel-filtration run of $\operatorname{rSbsC}_{(447-1099)}$ degraded by unidentified protease(s).

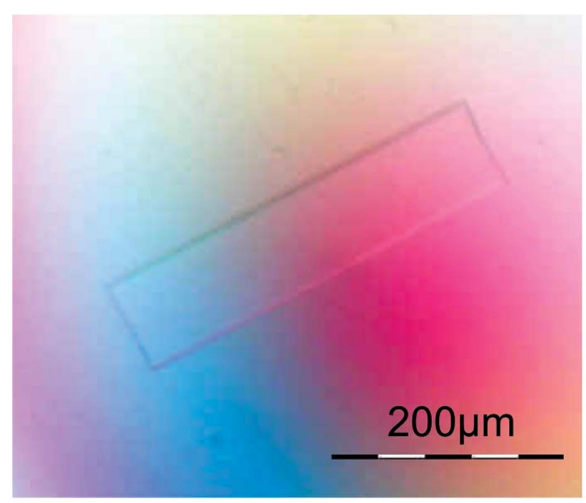

$(a)$

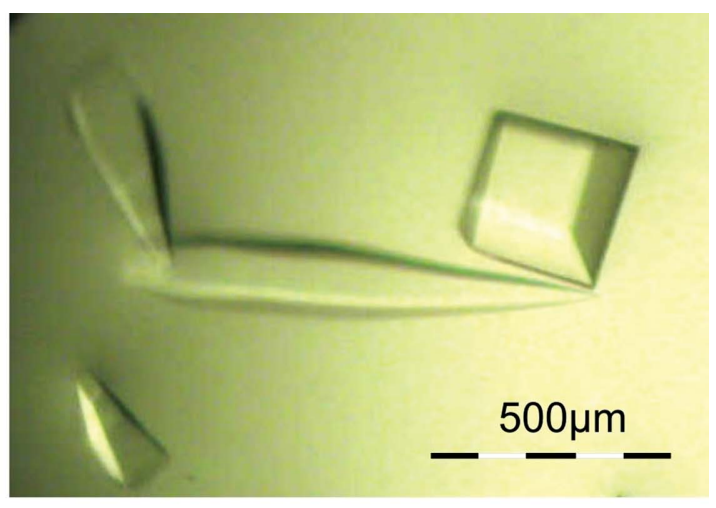

(b)

Figure 3

Typical crystals of $\operatorname{rSbsC}_{(755-1099)}$ grown in sitting-drop setups at $293 \mathrm{~K}$ in $(a)$ Index Screen condition 64 [0.005 $M$ cobalt chloride, nickel chloride, cadmium chloride and magnesium chloride, $0.1 M$ HEPES-NaOH pH 7.5, 12\%(w/v) PEG 3350] and (b) Index Screen condition 27 (2.4 $M$ sodium malonate $\mathrm{pH} 7.0)$. 
fragment $\mathrm{rSbsC}_{(751-959)}$ only diffracted to $9 \AA$ resolution, the longer fragment $\mathrm{rSbsC}_{(755-1099)}$ yielded crystals in four conditions, with the best crystals from each condition diffracting to a maximum resolution of between 5 and $2.6 \AA$. Diffracting crystals were obtained using conditions 27 (2.4 $M$ sodium malonate $\mathrm{pH} 7.0), 64$ [5 $\mathrm{mM}$ cobalt chloride, nickel chloride, cadmium chloride and magnesium chloride, $0.1 M$ HEPES-NaOH pH 7.5, 12\%( $w / v)$ PEG 3350], $90(0.2 M$ sodium formate, 20\% PEG 3350) and 93 (0.05 $M$ zinc acetate, $20 \%$ PEG 3350). The crystals appeared within $2-14 \mathrm{~d}$ in all conditions.

\section{Data collection and heavy-atom screening of rSbsC $_{(755-1099)}$}

Data collection was performed at $100 \mathrm{~K}$ and no cryoprotectant was needed to preserve the crystals. All tested crystals diffracted to limited resolution (weak spots to $5 \AA$ resolution in the best direction) at our home source (MicroStar, Bruker AXS, Karlsruhe, Germany) and native and derivative data sets were therefore collected on the synchrotron beamlines X11 (EMBL Outstation, Hamburg), XRDII (Swiss Light Source, Villigen) and XRD1 (Elettra, Trieste). The data sets were processed and scaled with DENZO and SCALEPACK (Otwinowski \& Minor, 1997).

The best native data set was collected from a $0.08 \times 0.35 \mathrm{~mm}$ crystal (Fig. $3 a$ ) obtained using refined condition 64 [4 $\mathrm{m} M$ cobalt chloride, nickel chloride, cadmium chloride and magnesium chloride, $0.08 M$ HEPES-NaOH pH 7.5, $10 \%(w / v)$ PEG 3350] in a vapourdiffusion sitting-drop setup. The crystal diffracted isotropically to $2.6 \AA$ resolution (Fig. $4 a$ ) and indexing yielded unit-cell parameters $a=68.6, b=170.5, c=93.6 \AA, \beta=92.1^{\circ}$ in space group $P 2_{1}$. The selfrotation function calculated with MOLREP (Collaborative Computational Project, Number 4, 1994) indicated the presence of six molecules in the asymmetric unit (see Table 1). All other tested crystals obtained from the same condition diffracted to significantly lower resolution and exhibited problems arising from pseudo-translation and twinning. The same problems were observed with crystals obtained from conditions 90 and 93. Therefore, all further heavyatom screening experiments and data collections were performed with crystals obtained from condition 27 (Fig. 3b). These crystals consistently showed anisotropic diffraction (Fig. $4 b$ ) to a maximum of $3 \AA$ resolution and belonged to the tetragonal space group $P 4_{1} 2{ }_{1} 2$ or $P 4_{3} 2_{1} 2$, with unit-cell parameters $a=b=67.8, c=312.8 \AA$, where the $c$ axes deviated up to $3 \%$ between different crystals (Fig. $4 b$ ). Using the gel-shift method of Boggon \& Shapiro (2000) to prescreen potential heavy-atom derivatives, we incubated the protein with various heavy atoms for $3-12 \mathrm{~h}$ and the samples were loaded onto $12 \%$ native PAGE. Potential derivatives were identified according to a gel shift on the native PAGE: potassium tetrachloroaureate, potassium osmate, ammonium hexabromoosmate, osmium chloride and di- $m$-iodobis(ethylenediamine)diplatinum nitrate (PIP). The same heavy atoms were used for the soaking of $\operatorname{rSbsC}_{(755-1099)}$ crystals, where soaks were performed from between $5 \mathrm{~min}$ and $24 \mathrm{~h}$. Colouring of the crystals was observed after 15-30 min when they were soaked with osmium and gold derivatives. Data sets were collected from crystals soaked with all previously described putative derivatives at the synchrotron and useful derivatives were selected according to isomorphous and anomalous Patterson maps calculated within CCP4 (Collaborative Computational Project, Number 4, 1994).

The heavy-atom sites found were confirmed with SHELXD (Sheldrick, 2008). The best derivative was obtained with $\mathrm{K}_{2} \mathrm{OsO}_{4}$ and showed strong and consistent peaks in anomalous as well as isomorphous Patterson maps. To determine the handedness of the space group, initial phasing was performed with SHELXE (Sheldrick, 2008), indicating $P 4_{1} 2{ }_{1} 2$ as being the correct space group. The selfrotation function showed no noncrystallographic symmetry, indicating the presence of one molecule in the asymmetric unit and an approximate solvent content of $74 \%$. Using a solvent content of $37 \%$, corresponding to two molecules in the asymmetric unit, no additional electron density was observed in the initial map generated by SHELXE (Sheldrick, 2008). Data-collection and processing statistics are shown in Table 1.

\section{Discussion}

The S-layer protein SbsC is an elongated multi-domain protein with inherent flexibility between the domains. This feature appears to be crucial for the biological functionality of the protein, namely its

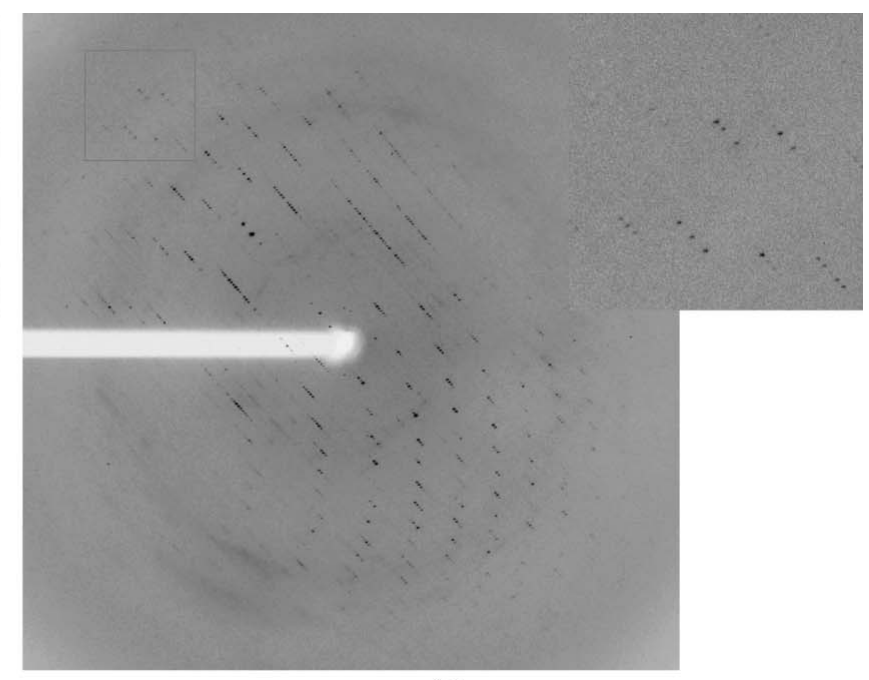

(b)

Figure 4

(a)

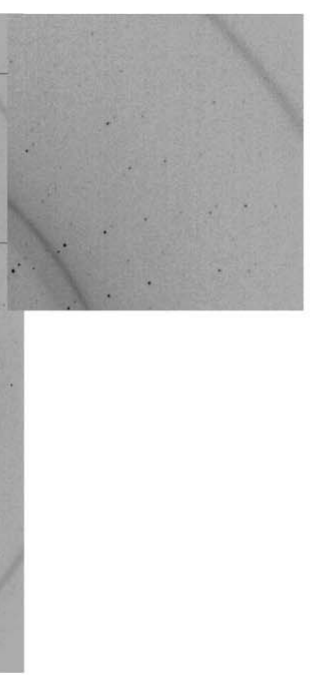

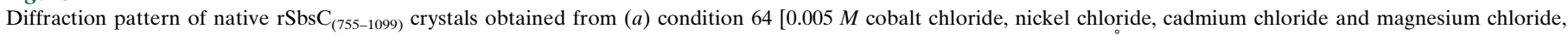

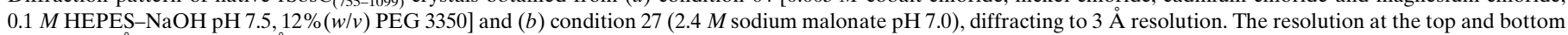
edges is $2.6 \AA$ in $(a)$ and $3.2 \AA$ in $(b)$. 
Table 1

Data-collection and processing statistics.

Data were collected at $100 \mathrm{~K}$. Values in parentheses are for the highest resolution shell.

\begin{tabular}{|c|c|c|c|}
\hline & \multirow{2}{*}{$\frac{\text { Condition } 64}{\text { Native }}$} & \multicolumn{2}{|l|}{ Condition 27} \\
\hline & & Native & Os derivative \\
\hline Beamline & X11, DESY, Hamburg & SLS, XRDII & SLS, XRDII \\
\hline Wavelength $(\AA)$ & 0.8148 & 1.1399 & 1.1399 \\
\hline Resolution range $(\AA)$ & $15-2.7(2.75-2.70)$ & $50-3.3(3.36-3.30)$ & $50-4.2(4.27-4.20)$ \\
\hline Space group & $P 2_{1}$ & $P 4_{1} 2_{1} 2$ & $P 4_{1} 2_{1} 2$ \\
\hline Unit-cell parameters $\left(\AA{ }^{\circ}\right)$ & $\begin{array}{c}a=68.6, b=170.5, c=93.6 \\
\alpha=90, \beta=92, \gamma=90\end{array}$ & $\begin{array}{c}a=68.1, b=68.1, c=313.1 \\
\alpha=\beta=\gamma=90\end{array}$ & $\begin{array}{c}a=68.7, b=68.7, c=316.2 \\
\alpha=\beta=\gamma=90\end{array}$ \\
\hline Measured reflections & 1528922 & 436979 & 555673 \\
\hline Unique reflections & 57458 & 10829 & 6096 \\
\hline Completeness (\%) & $96.7(78.6)$ & $91.1(54.8)$ & $98.4(83.4)$ \\
\hline Redundancy & $3.4(1.9)$ & $11.1(8.7)$ & $12.1(9.3)$ \\
\hline$\langle I / \sigma(I)\rangle$ & $9.9(2.5)$ & $15.9(1.6)$ & $19.9(2.8)$ \\
\hline$R_{\text {merge }}^{\dagger}(\%)$ & $11.8(33.8)$ & $10.8(67.5)$ & $13.4(49.6)$ \\
\hline$V_{\mathrm{M}}\left(\AA^{3} \mathrm{Da}^{-1}\right)$ & 2.34 & 4.65 & 4.78 \\
\hline Molecules per ASU & 6 & 1 & 1 \\
\hline Solvent content $(\%)$ & 47.4 & 73.6 & 73.9 \\
\hline
\end{tabular}

$\dagger R_{\text {merge }}=\sum_{h k l} \sum_{i}\left|I_{i}(h k l)-\langle I(h k l)\rangle\right| / \sum_{h k l} \sum_{i} I_{i}(h k l)$.

assembly properties on the bacterial surface and its attachment to the bacterial cell wall. However, such internal flexibility poses a major hurdle to obtaining high-quality three-dimensional crystals.

In addition, the lack of structural information from homologous proteins impedes the correct prediction of domain boundaries. Therefore, we chose the approach of generating soluble truncation mutants based on the recently obtained structure of the N-terminal part of SbsC (Pavkov et al., 2008). Since the last three domains of the $\mathrm{rSbsC}_{(31-844)}$ structure were poorly resolved and only the $\mathrm{C} \alpha$ chain could be traced, the assignments of the domain borders used for the new constructs, $\mathrm{rSbsC}_{(541-1099)}$ and $\mathrm{rSbsC}_{(638-1099)}$, were putative. In the case of unintentional in situ proteolysis, we observed two degradation fragments which turned out to be stable over a long time period. This implies that correct domain borders are conserved in the digestion process, yielding well folded subfragments. The larger of the subfragments, $\mathrm{rSbsC}_{(755-1099)}$, yielded the best diffracting crystals of the five $\mathrm{N}$-terminally truncated fragments tested.

Solution of the structure of $\mathrm{rSbsC}_{(755-1099)}$ using heavy-atom methods is in progress and will enable us to obtain atomic resolution information for a complete S-layer protein for the first time.

This work was supported by the Austrian Science Foundation (FWF projects P17885, P15040 and P18510-B12) and by the US Air Force Office of Scientific Research (Project FA9550-07-1-0313).

\section{References}

Avall-Jaaskelainen, S. \& Palva, A. (2005). FEMS Microbiol. Rev. 29, 511-529. Beveridge, T. J. (1994). Curr. Opin. Struct. Biol. 4, 204-212.

Beveridge, T. J. \& Koval, S. F. (1993). Editors. Advances in Bacterial Paracrystalline Surface Layers. New York, London: Plenum Press.

Boggon, T. J. \& Shapiro, L. (2000). Structure, 8, R143-R149.

Bohle, B., Breitwieser, A., Zwölfer, B., Jahn-Schmid, B., Sára, M., Sleytr, U. B. \& Ebner, C. (2004). J. Immunol. 172, 6642-6648.

Claus, H., Akca, E., Debaerdemaeker, T., Evrard, C., Declercq, J. P., Harris, J. R., Schlott, B. \& Konig, H. (2005). Can. J. Microbiol. 51, 731-743.

Collaborative Computational Project, Number 4 (1994). Acta Cryst. D50, 760-763.

Egelseer, E. M., Ilk, N., Pum, D., Messner, P., Schäffer, C., Schuster, B. \& Sleytr, U. B. (2009). In The Encyclopedia of Industrial Biotechnology: Bioprocess, Bioseparation, and Cell Technology, edited by M. C. Flickinger. Hoboken: John Wiley \& Sons. In the press.

Egelseer, E. M., Schocher, I., Sleytr, U. B. \& Sára, M. (1996). J. Bacteriol. 178, 5602-5609.

Engelhardt, H. (2007). J. Struct. Biol. 160, 115-124.
Fagan, R. P., Albesa-Jove, D., Qazi, O., Svergun, D. I., Brown, K. A. \& Fairweather, N. F. (2009). Mol. Microbiol. 71, 1308-1322.

Ferner-Ortner, J., Mader, C., Ilk, N., Sleytr, U. B. \& Egelseer, E. M. (2007). J. Bacteriol. 189, 7154-7158.

Ferner-Ortner-Bleckmann, J., Huber-Gries, C., Pavkov, T., Keller, W., Mader, C., Ilk, N., Sleytr, U. B. \& Egelseer, E. M. (2009). Mol. Microbiol. 72, 14481461

Jarosch, M., Egelseer, E. M., Huber, C., Moll, D., Mattanovich, D., Sleytr, U. B. \& Sára, M. (2001). Microbiology, 147, 1353-1363.

Jarosch, M., Egelseer, E. M., Mattanovich, D., Sleytr, U. B. \& Sára, M. (2000). Microbiology, 146, 273-281.

Jing, H., Takagi, J., Liu, J. H., Lindgren, S., Zhang, R. G., Joachimiak, A., Wang, J. H. \& Springer, T. A. (2002). Structure, 10, 1453-1464.

Messner, P., Egelseer, E. M., Schäffer, C. \& Sleytr, U. B. (2009). In Prokaryotic Cell Wall Compounds - Structure and Biochemistry, edited by H. König, H. Claus \& A. Varma. Heidelberg: Springer. In the press.

Messner, P., Pum, D., Sára, M., Stetter, K. O. \& Sleytr, U. B. (1986). J. Bacteriol. 166, 1046-1054.

Messner, P. \& Sleytr, U. B. (1992). Adv. Microb. Physiol. 33, 213-275.

Otwinowski, Z. \& Minor, W. (1997). Methods Enzymol. 276, 307-326.

Pavkov, T., Egelseer, E. M., Tesarz, M., Svergun, D. I., Sleytr, U. B. \& Keller, W. (2008). Structure, 16, 1226-1237.

Pavkov, T., Oberer, M., Egelseer, E. M., Sára, M., Sleytr, U. B. \& Keller, W. (2003). Acta Cryst. D59, 1466-1468.

Pum, D., Messner, P. \& Sleytr, U. B. (1991). J. Bacteriol. 173, 68656873.

Sára, M., Egelseer, E. M., Huber, C., Ilk, N., Pleschberger, M., Pum, D. \& Sleytr, U. B. (2006). Microbial Bionanotechnology: Biological Self-Assembly Systems and Biopolymer-based Nanostructures, edited by B. Rehm, pp. 307338. Norwich: Horizon Bioscience.

Sára, M., Pum, D., Huber, C., Ilk, N., Pleschberger, M. \& Sleytr, U. (2006). Biological and Pharmaceutical Nanomaterials. Nanotechnologies for the Life Sciences, edited by C. Kumar, pp. 219-252. Weinheim: Wiley-VCH.

Sára, M. \& Sleytr, U. B. (2000). J. Bacteriol. 182, 859-868.

Schäffer, C., Kählig, H., Christian, R., Schulz, G., Zayni, S. \& Messner, P. (1999). Microbiology, 145, 1575-1583.

Schuster, B. \& Sleytr, U. B. (2006). Curr. Nanosci. 2, 143-152.

Sheldrick, G. M. (2008). Acta Cryst. A64, 112-122.

Sleytr, U. B. (1975). Nature (London), 257, 400-402.

Sleytr, U. B. (1978). Int. Rev. Cytol. 53, 1-62.

Sleytr, U. B. \& Beveridge, T. J. (1999). Trends Microbiol. 7, 253-260.

Sleytr, U. B., Egelseer, E. M., Ilk, N., Pum, D. \& Schuster, B. (2007). FEBS J. 274, 323-334.

Sleytr, U. B. \& Glauert, A. M. (1975). J. Ultrastruct. Res. 50, 103-116.

Sleytr, U. B., Messner, P., Pum, D. \& Sára, M. (1993). Mol. Microbiol. 10, 911-916.

Sleytr, U. B., Messner, P., Pum, D. \& Sára, M. (1996). Crystalline Bacterial Cell Surface Proteins (S Layers), edited by U. B. Sleytr, P. Messner, D. Pum \& M. Sára, pp. 5-33. Austin: R. G. Landes Co./Academic Press.

Sleytr, U. B., Messner, P., Pum, D. \& Sára, M. (1999). Angew. Chem. Int. Ed. 38, 1034-1054. 
Sleytr, U. B., Pum, D., Schuster, B. \& Sára, M. (2001). Nano-Surface Chemistry, edited by M. Rosoff, pp. 333-389. New York, Basel: Marcel Dekker.

Sleytr, U. B. \& Sára, M. (1997). Trends Biotechnol. 15, 20-26.

Sleytr, U. B., Sára, M., Pum, D. \& Schuster, B. (2001). Prog. Surf. Sci. 68, 231-278.

Sleytr, U. B., Sára, M., Pum, D. \& Schuster, B. (2005). Supramolecular Polymers, 2nd ed., edited by A. Ciferri, pp. 583-612. Boca Raton:
CRC Press.

Sleytr, U. B., Sára, M., Pum, D., Schuster, B., Messner, P. \& Schäffer, C. (2002). Polyamides and Complex Proteinaceous Materials $I$, edited by A. Steinbüchel \& S. R. Fahnestock, pp. 285-338. Weinheim: Wiley-VCH.

Stetefeld, J., Jenny, M., Schulthess, T., Landwehr, R., Engel, J. \& Kammerer, R. A. (2000). Nature Struct. Biol. 7, 772-776. 